\title{
Effects of Ketamine in Normal and Schizophrenic Volunteers
}

\author{
Adrienne C. Lahti, M.D., Martin A. Weiler, M.D., Tamara Michaelidis B.A., Arti Parwani, M.D., and \\ Carol A. Tamminga, M.D.
}

This study evaluates the effects of ketamine on healthy and schizophrenic volunteers (SVS) in an effort to define the detailed behavioral effects of the drug in a psychosis model. We compared the effects of ketamine on normal and SVs to establish the comparability of their responses and the extent to which normal subjects might be used experimentally as a model. Eighteen normal volunteers (NVs) and $17 \mathrm{SVS}$ participated in ketamine interviews. Some $(\mathrm{n}=7 \mathrm{NVs} ; \mathrm{n}=9$ $S V s$ ) had four sessions with a 0.1-0.5 mg/kg of ketamine and a placebo; others ( $\mathrm{n}=11 \mathrm{NVs} ; \mathrm{n}=8 \mathrm{SVs}$ ) had two sessions with one dose of ketamine $(0.3 \mathrm{mg} / \mathrm{kg})$ and a placebo.

Experienced research clinicians used the BPRS to assess any change in mental status over time and documented the specifics in a timely way. In both volunteer groups, ketamine induced a dose-related, short ( $<30 \mathrm{~min}$ ) increase in psychotic symptoms. The scores of NVs increased on both the Brief Psychiatric Rating Scale (BPRS) psychosis subscale ( $\mathrm{p}=$ $.0001)$ and the BPRS withdrawal subscale $(\mathrm{p}=.0001)$, whereas SVs experienced an increase only in positive symptoms $(\mathrm{p}=.0001)$. Seventy percent of the patients reported an increase (i.e., exacerbation) of previously experienced positive symptoms. Normal and schizophrenic groups differed only on the BPRS withdrawal score. The magnitude of ketamine-induced changes in positive symptoms was similar, although the psychosis baseline differed, and the dose-response profiles over time were superimposable across the two populations. The similarity between ketamine-induced symptoms in $S V$ s and their own positive symptoms suggests that ketamine provides a unique model of psychosis in human volunteers. The data suggest that the phencyclidine (PCP) model of schizophrenia maybe a more valid human psychosis/ schizophrenia drug model than the amphetamine model, with a broader range of psychotic symptoms. This study indicates that NVs could be used for many informative experimental psychosis studies involving ketamine interviews.

[Neuropsychopharmacology 25:455-467, 2001] (C) 2001 American College of Neuropsychopharmacology. Published by Elsevier Science Inc.
KEY WORDS: Schizophrenia; Ketamine; Psychosis; N-methyl-D-aspartate; Glutamate; Drug model

Ketamine is an anesthetic drug and a noncompetitive NMDA antagonist, with mild psychotomimetic proper-

From the Maryland Psychiatric Research Center, University of Maryland School of Medicine, Baltimore, MD.

Address correspondence to: Adrienne C. Lahti, M.D., Maryland Psychiatric Research Center, University of Maryland School of Medicine, P.O. Box 21247, Baltimore, MD 21228.

Received May 25, 2000; revised January 24, 2001; accepted February $12,2001$.

Online publication: 2/20/01 at www.acnp.org/citations/ Npp02200182 ties. It is one of the only pharmacologic probes of the NMDA-sensitive glutamate system available for human study. The proposal that human studies with ketamine will inform the study of schizophrenia is based on preclinical evidence (Carlsson and Carlsson 1990; Javitt and Zukin 1991; Coyle and Puttfarcken 1993; Olney and Farber 1995) and clinical evidence (Krystal et al. 1994; Lahti et al. 1995a; Malhotra et al. 1997a) of the potential involvement of glutamate in schizophrenia.

Both normal and schizophrenic volunteers (SVs) received ketamine under controlled experimental conditions to explore the hypothesis that the drug provides a valid drug model for schizophrenia with a broad range 
of induced symptoms. This study critically evaluates the effects of ketamine on mental status in normal volunteers (NVs) and SVs and defines the detailed behavioral effects of the drug in a psychosis model.

Several other psychotomimetic compounds have been examined as a potential drug model for schizophrenia. Indirect-acting dopamine agonists, such as amphetamine or methylphenidate, have provided a widely accepted model of paranoid schizophrenia. Both drugs have been studied in NVs and SVs in controlled research conditions. A single acute challenge with lowdose psychostimulant in schizophrenic patients induces a heterogeneous response, either improving or worsening mental status (vanKammen et al. 1982). High-dose repeated administration of amphetamine to NVs can produce paranoid symptoms that resemble paranoid schizophrenia in normal persons (Connell 1958; Griffith et al. 1968; Angrist and Gershon 1970; Bell 1973).

The psychotomimetic indoleamines: d-lysergic acid diethylamide (LSD) and psilocybin, both structural analogues of serotonin-have been studied in humans. Both drugs act as agonists at serotonin receptors, most potently at the 5HT2 receptor (Aghajanian and Marek 1999). The state induced by these drugs in normal subjects is commonly described as a "psychedelic experience," with vivid hallucinatory experience, fusion of visual and other sensory experiences, and emotional alterations (Langs and Barr 1968; Giannini 1994; Vollenweider et al. 1998).

Interest in the role of excitatory neurotransmitter systems in the pathophysiology of schizophrenia developed from two observations. First, phencyclidine (PCP) produces schizophrenia-like symptoms in humans (Luby et al. 1959). Second, PCP noncompetitively blocks ion flow through the NMDA-sensitive glutamate receptor ionophore (Anis et al. 1983). Ketamine is a structural analogue of $\mathrm{PCP}$, which binds to the PCP site of the NMDA receptor with about one tenth the potency of PCP (Kornhuber and Weller 1995). At higher doses ketamine, like PCP, has broader neurochemical actions (Tonge and Leonard 1969; Raja and Guyenet 1980; Castellani and Adams 1981; Nabeshima et al. 1981; Malare et al. 1982). Ketamine is made of a racemic mixture with the S-enantioner displaying a 3-4 higher affinity for the NMDA receptor than the R-ketamine (Oye et al. 1991).

Challenge and symptom provocation studies are currently held to stricter ethical standards than other human research. They must include a clinically significant theoretical rationale, involve a careful risk-benefit discussion with the volunteer resulting in informed consent, and use persons with a brain disease only if healthy volunteers cannot be substituted. Therefore, this study compares the effect of ketamine on NVs and SVs to establish whether control subjects could be used informatively in future studies.

\section{METHODS}

\section{Participants}

Normal Volunteers. To recruit healthy volunteers, we used newspaper advertising. A social worker screened them in a structured telephone interview, and then a trained research assistant interviewed them face to face using the Structural Clinical Interview Diagnosis (SCID) (Spitzer et al. 1990), the Structural Clinical Interview for Personality Diagnosis (SCID-P) (Stangl et al. 1985), and the Wisconsin Scales of Psychosis Proneness (Chapman et al. 1994). These Psychosis Proneness scales were developed to rate features of schizotypal personality disorder. Of the seven scales, we chose five for this study: Perceptual Aberration, Social Anhedonia, Physical Anhedonia, Magical Ideation, and Nonconformity. A psychiatrist interviewed the NVs to review any questions raised during screening and to verify diagnosis. All participants received a physical examination and EKG. Laboratory plasma and urine samples were also obtained, including HIV testing and a drug screen.

The exclusion criteria included any history of an axis I or II psychiatric disorder (including substance abuse), any first-degree relatives with a diagnosis of schizophrenia, any major medical diagnosis, any abnormal chemical screen, or high blood pressure. We informed volunteers that they may have random toxicologic urine screens. Participants were paid $\$ 10 / \mathrm{h}$ for participating in this study.

Eighteen healthy volunteers received ketamine interviews, 14 males and four females, 14 Caucasians and four African Americans. The mean age of the volunteers was $29.4( \pm 5.5)$ years and their mean weight was $175.2( \pm 32.1)$ pounds.

Schizophrenic Volunteers. We recruited SVs from the group of voluntary inpatients on the Residential Research Unit (RRU) of the MPRC. Patients on the RRU are recruited from Maryland to participate in on-going research protocols. Before hospitalization, we informed candidates about the research nature of the program and encouraged them to visit and examine the facilities. Patient volunteers have active but stable symptoms requiring hospitalization and/or have experienced several reoccurrences of the illness and require supervised residential care.

Two experienced clinicians gave SVs a psychiatric diagnosis of schizophrenia using DSM-III-R criteria based on all of the historical and direct assessment information available. We evaluated each participant using the Structured Clinical Interview Diagnosis (SCID), the Schedule for the Deficit Syndrome (SDS) (Kirkpatrick et al. 1989), the MPRC Involuntary Movement Scale (IMS) (Cassady et al. 1997), the Cannon-Spoor Premorbid Adjustment Scale (PAS) (Cannon-Spoor et al. 
1982), and the Prognostic Scale (PRO) (Strauss and Carpenter 1974). Moreover, each participant had a detailed clinical psychiatric history and family history of mental illness and had extensive contact with past treatment facilities and family members, when available. Each subject was medically healthy by history and free of current significant disease by physical exam, EKG, and laboratory examination. None of these volunteers had a recent history of drug or alcohol abuse. We used these exclusion criteria: any major medical diagnoses, an abnormal plasma chemical screen, or high blood pressure. All SVs were on a fixed dose of haloperidol (HAL) (0.3 $\mathrm{mg} / \mathrm{kg} /$ day) for four weeks before the first ketamine interview. SVs were not paid for their participation in this study. Seventeen SVs received ketamine interviews. For their demographic characteristics, see Table 1.

Informed Consent. We fully informed all of the NVs and SVs about the nature of the protocol and the potential side effects of ketamine, including psychosis exacerbation. Afterward, each gave informed consent. Obtaining consent with SVs was a more lengthy process than with the NVs, who signed consent after the research team [including the Principal Investigator (P.I.)] informed them and answered their questions. Only patients who were judged to be competent and clinically capable of understanding and appreciating the risks involved in these studies were selected to participate. This selection was made by a clinician; an indepen- dently designated State of Maryland Mental Health Administration (MHA) employee confirmed the ability of the volunteer to understand the nature of the research.

For patient volunteers, several people presented the nature of the protocol, including the P.I. We involved family members or care-givers in the information process when they were available. We gave patients detailed verbal descriptions of the procedures and risks described in the protocol. After being informed, they were required to document their understanding by listing key features and risks of the protocol. A designated RRU ombudsperson was responsible for monitoring the quality of the consent procedures and working closely with patients throughout the research project, reinforcing the requirements and risks of the protocol. The roles of the independent MHA representative and the MPRC ombudsperson were instituted in 1998.

The University of Maryland Internal Review Board (IRB) approved the protocol and consent form. The IRB initially approved the research and gave detailed and ongoing review of this project, especially when the mental status consequences of ketamine in schizophrenia became apparent.

\section{Ketamine Administration Procedure}

We conducted the ketamine interviews in the same way for NVs and SVs-either four sessions with a dose range of ketamine $(0.1-0.5 \mathrm{mg} / \mathrm{kg})$ and a placebo, or

Table 1. Demographics: Schizophrenic Volunteers

\begin{tabular}{|c|c|c|c|c|c|c|c|c|c|c|c|}
\hline Patient \# & Sex & Race & Age & $\begin{array}{c}\text { Length of } \\
\text { Illness (years) }\end{array}$ & Diagnosis & $\begin{array}{c}\text { BPRS }^{a} \\
\text { Total } \\
\text { Score }\end{array}$ & $\begin{array}{l}\text { BPRS }^{a} \\
\text { Psychosis } \\
\text { Score }\end{array}$ & $\begin{array}{c}\text { Deficit }^{b} \\
\text { Symptoms }\end{array}$ & PAS $^{c}$ & $\mathbf{P R O}^{\mathrm{d}}$ & Weight $^{\mathbf{e}}$ \\
\hline 1 & $\mathrm{~F}$ & $\mathrm{~A}$ & 28 & 9 & Schizo./paranoid & 38 & 3 & $x$ & 0.2 & 2 & 132 \\
\hline 2 & $\mathrm{~F}$ & AA & 28 & 4 & Paranoid & 24 & 3 & $X$ & 0.01 & 1 & 165 \\
\hline 3 & M & $\mathrm{C}$ & 28 & 8 & Paranoid & 32 & 6 & & 0.27 & 5 & 154 \\
\hline 4 & M & $\mathrm{C}$ & 23 & 7 & Disorg. & 36 & 8 & & 0.26 & 1 & 142 \\
\hline 5 & M & $\mathrm{C}$ & 22 & 3 & Paranoid & 41 & 6 & & 0.48 & 6 & 166 \\
\hline 6 & M & AA & 25 & 8 & Paranoid & 36 & 5 & & 0.03 & 5 & 162 \\
\hline 7 & M & $\mathrm{AA}$ & 29 & 8 & Paranoid & 42 & 6 & & 0.15 & 5 & 209 \\
\hline 8 & $\mathrm{~F}$ & A & 53 & 24 & Undiff. & 35 & 10 & $x$ & 0.22 & 0 & 143 \\
\hline 9 & $\mathrm{~F}$ & $\mathrm{C}$ & 34 & 13 & Undiff. & 33 & 12 & & 0.56 & 0 & 118 \\
\hline 10 & M & $\mathrm{C}$ & 35 & 19 & Undiff. & 27 & 5 & & 0.12 & 5 & 166 \\
\hline 11 & M & AA & 30 & 14 & Paranoid & 44 & 10 & & 0.46 & 1 & 184 \\
\hline 12 & M & $\mathrm{C}$ & 36 & 17 & Undiff. & 43 & 7 & $X$ & 0.31 & 3 & 152 \\
\hline 13 & $\mathrm{~F}$ & C & 39 & 8 & Paranoid & 25 & 8 & & 0.15 & 5 & 132 \\
\hline 14 & M & $\mathrm{C}$ & 37 & 26 & Undiff. & 36 & 9 & & 0.7 & 4 & 184 \\
\hline 15 & M & $\mathrm{C}$ & 26 & 9 & Disorg. & 42 & 13 & & 0.42 & 4 & 158 \\
\hline 16 & $\mathrm{~F}$ & AA & 25 & 10 & Undiff. & 21 & 5 & & 0.44 & 3 & 228 \\
\hline \multirow[t]{3}{*}{17} & $\mathrm{M}$ & $\mathrm{C}$ & 39 & 22 & Undiff. & 27 & 8 & & 0.54 & 8 & 232 \\
\hline & Mean \pm SD & & 31.6 & 12.3 & & 34.2 & 7.3 & & 0.3 & 3.4 & 166.3 \\
\hline & & & \pm 7.8 & \pm 7.0 & & \pm 7.2 & \pm 2.9 & & \pm 0.2 & \pm 2.3 & \pm 32.4 \\
\hline
\end{tabular}

Abbreviations: AA, African American; A, Asian; C, Caucasian; schizo., schizophrenia; disorg., disorganized; undiff., undifferentiated.

aPRS Total and Psychosis Scores at baseline.

brimary negative symptoms.

'Premorbid Adjustment Scale: Age Scales Total Score (lower score is better).

dPrognostic Scale: General Items Total Score (higher score is better).

ein pounds. 
two sessions with one dose of ketamine $(0.3 \mathrm{mg} / \mathrm{kg})$ and a placebo. Each dose or placebo was administered as a bolus over $60 \mathrm{~s}$ in a double-blind fashion. One dose was given on each of two or four different days over two weeks. Typically, subjects were never studied on two consecutive days. One physician (CT) and one research nurse were not blind to drugs but were not involved in clinical assessments. The order of the drugs was random, except that the highest dose was not routinely given first.

On the day of the experiment and $1 \mathrm{~h}$ before injection, an indwelling catheter was placed in the forearm while the patient was comfortably positioned in a quiet room with familiar staff members. We used an EKG monitor to monitor cardiac status continuously for 30 min after ketamine; we closely monitored pulse, blood pressure, and blood oxygen saturation. We rated mental status at baseline and 20,90, and $180 \mathrm{~min}$ after drug administration.

\section{Mental Status Evaluation}

We evaluated mental status using the Brief Psychiatric Rating Scale (BPRS) (Overall and Gorham 1962). The BPRS was used to evaluate subjects on the day of the infusion before administering ketamine/placebo and after drug injection at 20,90, and $180 \mathrm{~min}$. We evaluated the BPRS total score as well as its subscale scores (Hedlund and Vieweg 1980): psychosis (items: conceptual disorganization, hallucinatory behavioral, and unusual thought content); withdrawal (emotional withdrawal, motor retardation, and blunted affect); activation (items: tension, mannerisms and posturing, and excitement); anxiety (items: somatic concern, anxiety, guilt feelings, and depressive mood); hostility (items: hostility, suspiciousness, and uncooperativeness).

Experienced research clinicians blind to dose or drug status conducted the mental status; each volunteer's ketamine series was rated by the same clinician. Raters are trained and re-trained periodically on the BPRS to maintain adequate reliability. These are the representative intraclass correlation coefficients for RRU raters for the BPRS total and subscale scores: 0.86 for the BPRS thought subscale and 0.73 for the BPRS total score. To produce a timely written record of the responses, the blinded clinician took detailed clinical notes. The same clinician conducted a follow-up clinical interview while still blind to the drug or dose at $8 \mathrm{~h}$ and $24 \mathrm{~h}$ after injection.

\section{Plasma Assays}

We obtained blood samples for ketamine levels at the $0.3 \mathrm{mg} / \mathrm{kg}$ challenge at baseline, 10, 20, 30, and $60 \mathrm{~min}$ after ketamine bolus infusion. We rapidly processed the blood samples in a refrigerated centrifuge and stored the plasma samples at $-80^{\circ} \mathrm{C}$. Plasma ketamine and norketamine were assayed in the laboratory of Thomas
Cooper (Nathan Klein Institute, Orangeburg, NY), using a validated liquid chromatographic (LC) procedure with UV detection. Following the addition of $500 \mathrm{ng}$ of internal standard (2-phenylmorphoinol, BW 306U), ketamine, and the metabolite norketamine were extracted from $1 \mathrm{ml}$ of plasma, made alkaline with $0.5 \mathrm{M} \mathrm{NaOH}$, with $5.0 \mathrm{ml}$ of $1.5 \%$ isoamyl alcohol in n-heptane.

The organic extract was back-extracted with $0.25 \mathrm{ml}$ of $0.01 \mathrm{M} \mathrm{HCI}$ and transferred to inserts for injection on the LC. Chromatography was carried out using a trimethylsilyl bonded silica column (LC-1, Supelco) with a mobile phase of $85 \%$ phosphate buffer, $15 \%$ acetonitrile, adjusted to $\mathrm{pH}$ of 2.4 with phosphoric acid, triethylamine, and heptane sulfonate. At a flow rate of $2.0 \mathrm{ml} / \mathrm{min}$, ketamine, norketamine, and the internal standard were separated and detected at a UV wavelength of $210 \mathrm{~nm}$ in less than $12 \mathrm{~min}$.

\section{Statistical Analysis}

To test the effects of ketamine on mental status, we analyzed BPRS total and subscale scores. For the single dose dataset $(\mathrm{NVs}=18, \mathrm{SVs}=17)$, we performed a univariate repeated measures analysis of variance to test for a main effect of group (NVs, SVs) and two repeated measures: dose (placebo, $0.3 \mathrm{mg} / \mathrm{kg}$ ) and time (baseline, 20", 90", 180"). We used a Greenhouse-Geisser correction following significant dose-by-time interactions, and we used post-hoc contrasts to contrast each time point to baseline. All repeated measures effects are reported with the original degrees of freedom and Greenhouse-Geisser corrected $p$-values. Subsequently, we analyzed both groups separately, using the same dose and time repeated measures. Changes in BPRS total, psychosis, and withdrawal scores were predicted a-priori. Therefore, the analyses of these variables were treated as planned comparisons with an $\alpha$ value of 0.05 . The analyses of other BPRS subscales were subjected to a Bonferroni correction $(\alpha=0.017)$.

A subset of volunteers in the single-dose dataset received two additional ketamine doses $(\mathrm{NVs}=7, \mathrm{SVs}=$ 9). These data were analyzed by a corrected univariate repeated measures analysis of variance, as described above, with four repeated doses (placebo, $0.1 \mathrm{mg} / \mathrm{kg}$, $0.3 \mathrm{mg} / \mathrm{kg}, 0.5 \mathrm{mg} / \mathrm{kg}$ ).

For SVs, we correlated demographic descriptors: age, baseline symptomology, age of onset of symptoms, and length of illness, against BPRS total and subscale scores at $0.3 \mathrm{mg} / \mathrm{kg}$ and $20 \mathrm{~min}$, using Pearson's Product Moment correlations. We analyzed the effects of sex, race, diagnosis, and deficit symptomology on BPRS scores individually by a univariate analysis of variance.

Ten schizophrenic patients had a period of antipsychotic medication withdrawal lasting at least four weeks as part of another approved research protocol. There were no links between the withdrawal and ketamine studies; thus various time intervals elapsed be- 
tween them. During the medication withdrawal period, we obtained weekly ratings from blind clinicians using the BPRS. We correlated the changes in BPRS ratings over four weeks of medication withdrawal with each subject's ketamine behavioral change scores at $20 \mathrm{~min}$ (from baseline) at $0.3 \mathrm{mg} / \mathrm{kg}$, using Pearson's Product Moment Correlations.

For NVs, we correlated the demographic descriptor of age with BPRS total and subscale scores at $0.3 \mathrm{mg} / \mathrm{kg}$ and 20 min, using Pearson's Product Moment Correlations. We analyzed the effects of sex and race on BPRS scores individually by a univariate analysis of variance. We correlated the Wisconsin scale scores with BPRS total and subscale scores at $0.3 \mathrm{mg} / \mathrm{kg}$ and $20 \mathrm{~min}$, using Pearson's Product Moment Correlations.

\section{RESULTS}

Eighteen NVs and $17 \mathrm{SVs}$ received an interview with $0.3 \mathrm{mg} / \mathrm{kg}$ ketamine and a placebo. Of those, seven $\mathrm{NVs}$ and nine SVs received the complete dose curve and a placebo. We did the full dose curve first to establish the optimal dose for the interview. After that, only one drug dose $(0.3 \mathrm{mg} / \mathrm{kg})$ was used with placebo. This was the lowest dose, which most consistently produced a ratable psychotomimetic effect.

\section{Single Dose vs. Placebo}

Normal Volunteers. In NVs, there was a significant time-by-dose interaction for: the BPRS total score $(\mathrm{F}[3,51]=68.10 ; p=.0001)$; the BPRS psychosis score $(\mathrm{F}[3,51]=59.64 ; p=.0001)$; the BPRS withdrawal score $(\mathrm{F}[3,51]=59.12 ; p=.0001)$.
Post-hoc analyses showed that compared to placebo the increase from baseline was significant at $20 \mathrm{~min}$ for the BPRS total and several subscales: the BPRS total $(\mathrm{F}[1,17]=62.71 ; p=.0001)$, the BPRS psychosis $(\mathrm{F}[1,17]=$ $72.15 ; p=.0001)$, and the BPRS withdrawal $(\mathrm{F}[1,17]=$ 56.67; $p=.0001$ ). See Table 2a for means (mean change score) and standard deviations (SD).

In summary, in NVs the BPRS total, psychosis, and withdrawal scores increased significantly at $20 \mathrm{~min}$, but not at 90 or $180 \mathrm{~min}$ after ketamine. Placebo did not produce this pattern (Figure 1).

Schizophrenic Volunteers. In SVs, there was a significant time-by-dose interaction for the BPRS total $(\mathrm{F}[3,48]=$ $7.75 ; p=.0037)$ and the BPRS psychosis $(\mathrm{F}[3,48]=$ 21.94; $p=.0001$ ) scores. Post-hoc analyses revealed an increase at the 20-min rating for ketamine for the BPRS total $(\mathrm{F}[1,16]=10.45 ; p=.0052)$ and the BPRS psychosis $(\mathrm{F}[1,16]=24.84 ; p=.0001)$. Ketamine did not significantly effect the withdrawal score. See Table 2a for means and SD.

In summary, in SVs the BPRS total and psychosis scores, but not the withdrawal score, significantly increased at $20 \mathrm{~min}$, but not 90 or $180 \mathrm{~min}$ after ketamine. Placebo did not produce this pattern (Figure 1).

\section{Multiple Dose vs. Placebo}

Normal Volunteers. Among NVs, there was a significant time-by-dose interaction for: the BPRS total $(\mathrm{F}[9,54]=$ $43.58 ; p=.0001)$; the BPRS psychosis $(\mathrm{F}[9,54]=12.20 ; p=$ $.0001)$; the BPRS withdrawal $(\mathrm{F}[9,54]=12.45 ; p=.001)$; and the BPRS anxiety score $(\mathrm{F}[9,54]=4.39 ; p=.0026)$.

Post-hoc analyses showed that compared to placebo an increase occurred at $20 \mathrm{~min}$ for all three ketamine

Table 2a. BPRS Change Scores after Ketamine $(0.3 \mathrm{mg} / \mathrm{kg})$ and Placebo

\begin{tabular}{|c|c|c|c|c|c|c|c|c|c|c|c|c|c|}
\hline \multirow[b]{2}{*}{ Dose } & \multirow[b]{2}{*}{ Time } & \multicolumn{4}{|c|}{$\begin{array}{l}\text { BPRS } \\
\text { Total }\end{array}$} & \multicolumn{4}{|c|}{$\begin{array}{c}\text { BPRS } \\
\text { Psychosis }\end{array}$} & \multicolumn{4}{|c|}{$\begin{array}{c}\text { BPRS } \\
\text { Withdrawal }\end{array}$} \\
\hline & & SV & SD & NV & sd & SV & sd & NV & sd & SV & sd & NV & sd \\
\hline PBO & $20^{\prime}$ & -0.9 & -3 & -0.1 & 1.3 & 0.1 & 0.8 & 0.1 & 0.2 & 0.2 & 0.8 & 0.1 & 0.2 \\
\hline $0.3 \mathrm{mg}$ & $20^{\prime}$ & 6.8 & -9 & 8.7 & 4.1 & 3.3 & 2.4 & 3.5 & 1.8 & 1 & 3.1 & 3.4 & 1.9 \\
\hline $\mathrm{PBO}$ & $90^{\prime}$ & -1.9 & -3.3 & -0.8 & 1.1 & -0.1 & 0.2 & 0 & 0 & -0.1 & 0.6 & 0.1 & 0.2 \\
\hline $0.3 \mathrm{mg}$ & $90^{\prime}$ & -1.1 & -3.5 & -0.4 & 1.7 & 0.4 & 0.9 & 0.2 & 0.6 & -0.8 & 1.8 & -0.1 & 0.2 \\
\hline $\mathrm{PBO}$ & $180^{\prime}$ & -2.6 & -4.1 & -0.7 & 1.1 & -0.1 & 0.3 & 0 & 0 & -0.4 & 0.9 & 0.1 & 0.2 \\
\hline \multirow[t]{2}{*}{$0.3 \mathrm{mg}$} & $180^{\prime}$ & -1.1 & -2.7 & -0.8 & 1.4 & 0.4 & 0.7 & 0.1 & 0.5 & -0.8 & 1.9 & -0.1 & 0.2 \\
\hline & & \multicolumn{4}{|c|}{$\begin{array}{l}\text { BPRS } \\
\text { Anxiety }\end{array}$} & \multicolumn{4}{|c|}{$\begin{array}{c}\text { BPRS } \\
\text { Activation }\end{array}$} & \multicolumn{4}{|c|}{$\begin{array}{c}\text { BPRS } \\
\text { Hostility }\end{array}$} \\
\hline $\mathrm{PBO}$ & $20^{\prime}$ & -0.7 & 1.9 & -0.2 & 1.1 & 0.3 & 0.5 & 0 & 0. & -0.1 & 0.6 & 0 & 0 \\
\hline $0.3 \mathrm{mg}$ & $20^{\prime}$ & 0.1 & 3.9 & 0.7 & 1.5 & 1.4 & 3.2 & 0.1 & 0. & 0.6 & 2.1 & 0.2 & 0.4 \\
\hline $\mathrm{PBO}$ & $90^{\prime}$ & -1.5 & 2 & -0.8 & 0.9 & -0.2 & 0.8 & -0.1 & 0.2 & 0.1 & 0.7 & 0 & 0 \\
\hline $0.3 \mathrm{mg}$ & $90^{\prime}$ & -0.9 & 2.1 & -0.7 & 1 & 0 & 0.9 & 0.1 & 0.5 & -0.1 & 1.3 & 0 & 0 \\
\hline $\mathrm{PBO}$ & $180^{\prime}$ & -1.4 & 2.2 & -0.7 & 0.9 & -0.4 & 0.9 & -0.1 & 0.2 & -0.2 & 0.6 & 0 & 0 \\
\hline $0.3 \mathrm{mg}$ & $180^{\prime}$ & -0.8 & 1.5 & -0.8 & 1 & -0.1 & 0.7 & -0.1 & 0.2 & -0.1 & 0.9 & 0 & 0 \\
\hline
\end{tabular}

SV $N=17$

$\mathrm{NV} N=18$. 

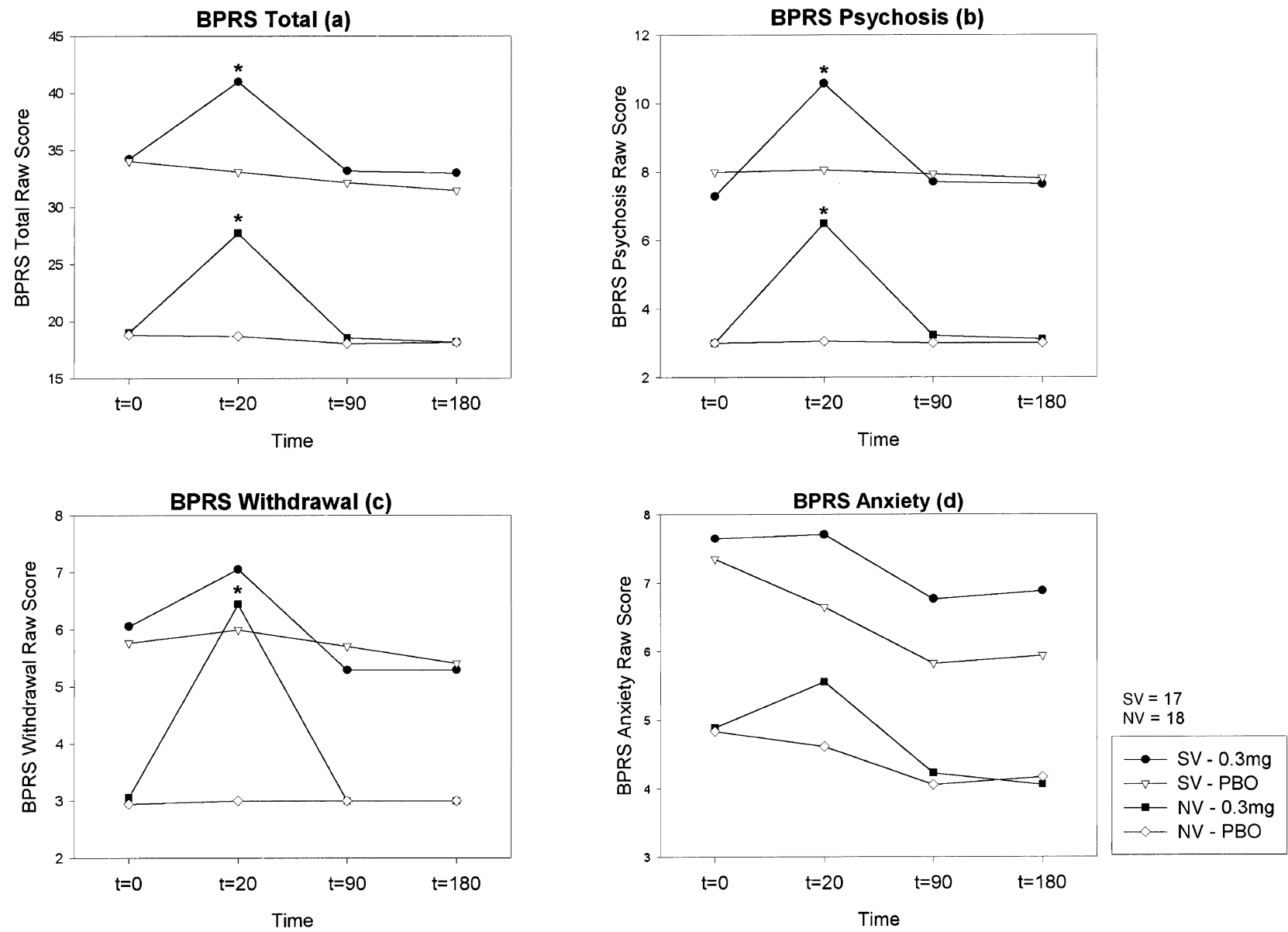

Figure 1. Time course of mental status after acute injection of ketamine $0.3 \mathrm{mg} / \mathrm{kg}$ (closed symbols) and placebo (open symbols) in normal $(n=18)$ and SVs $(n=17)$. Mean BPRS total and subscales scores are shown. Asterisk indicates a significant increase in mean change score at a given time point. The BPRS total and psychosis change scores were significantly increased at $20 \mathrm{~min}$ after ketamine in both volunteer populations. The BPRS withdrawal change scores were significantly increased at 20 min only in NVs. For both populations, there were no significant increases in the BPRS anxiety change scores at any time after ketamine.

doses in the BPRS total score $(0.1 \mathrm{mg} / \mathrm{kg}: \mathrm{F}[1,6]=10.8$; $p=.0167)(0.3 \mathrm{mg} / \mathrm{kg}: \mathrm{F}[1,6]=51.69 ; p=.0004)(0.5$ $\mathrm{mg} / \mathrm{kg}: \mathrm{F}[1,6]=122 ; p=.0001)$ and the BPRS psychosis score $(0.1 \mathrm{mg} / \mathrm{kg}: \mathrm{F}[1,6]=22.74 ; p=.0031)(0.3 \mathrm{mg} / \mathrm{kg}$ : $\mathrm{F}[1,6]=18.18 ; p=.0053)(0.5 \mathrm{mg} / \mathrm{kg}: \mathrm{F}[1,6]=26.03 ; p=$ .0022). On the BPRS withdrawal score, an increase was evident at $20 \mathrm{~min}$ only for the 0.3 and $0.5 \mathrm{mg} / \mathrm{kg}$ doses $(0.3 \mathrm{mg} / \mathrm{kg}: \mathrm{F}[1,6]=13.56 ; p=.0103)(0.5 \mathrm{mg} / \mathrm{kg}: \mathrm{F}[1,6]=$ $12.79 ; p=.0117)$. For the BPRS anxiety score, an increase at a trend level occurred only at $20 \mathrm{~min}$ for the $0.5 \mathrm{mg} / \mathrm{kg}$ dose $(0.5 \mathrm{mg} / \mathrm{kg}: \mathrm{F}[1,6]=8.24 ; p=.0284)$. See Table $2 b$ for means and SD.

In summary, in NVs the BPRS total and psychosis scores increased significantly at $20 \mathrm{~min}$, but not at 90 or 180 min after ketamine, for all three ketamine doses. The BPRS withdrawal score increased significantly at 0.3 and $0.5 \mathrm{mg} / \mathrm{kg}$ at $20 \mathrm{~min}$, but not at 90 or $180 \mathrm{~min}$ and not at $0.1 \mathrm{mg} / \mathrm{kg}$. There was a trend for the BPRS anxiety score to be elevated at $0.5 \mathrm{mg} / \mathrm{kg}$ at $20 \mathrm{~min}$ (Figure 2).
Schizophrenic Volunteers. There was a significant timeby-dose interaction for the BPRS total score $(\mathrm{F}[9,72]=$ $4.21 ; p=.0012)$ and the BPRS psychosis score $(\mathrm{F}[9,72]=$ $6.10 ; p=.0006)$.

For the BPRS total score $(0.1 \mathrm{mg} / \mathrm{kg}: \mathrm{F}[1,8]=5.33 ; p=$ $.0497 ; 0.3 \mathrm{mg} / \mathrm{kg}: \mathrm{F}[1,8]=7.24 ; p=.0275 ; 0.5 \mathrm{mg} / \mathrm{kg}$ : $\mathrm{F}[1,8]=13.75 ; p=.006)$, and the BPRS psychosis score $(0.1 \mathrm{mg} / \mathrm{kg}: \mathrm{F}[1,8]=33.11 ; p=.0004 ; 0.3 \mathrm{mg} / \mathrm{kg}: \mathrm{F}[1,8]=$ $13.96 ; p=.0057 ; 0.5 \mathrm{mg} / \mathrm{kg}: \mathrm{F}[1,8]=17.31 ; p=.0032)$, the increase was apparent at $20 \mathrm{~min}$ for all three ketamine doses. No drug effects on the withdrawal score was apparent. See Table $2 b$ for means and SD.

In summary, in SVs the BPRS total and psychosis scores significantly increased at $20 \mathrm{~min}$, but not at 90 or $180 \mathrm{~min}$ after ketamine, for all three ketamine doses. See Figure 2.

Comparing Normal and Schizophrenic Volunteers Single Dose. There was a main effect for group on all BPRS subscales: $(\mathrm{BPRS}$ total $\mathrm{F}[1,33]=88.17 ; p=.0001$; 

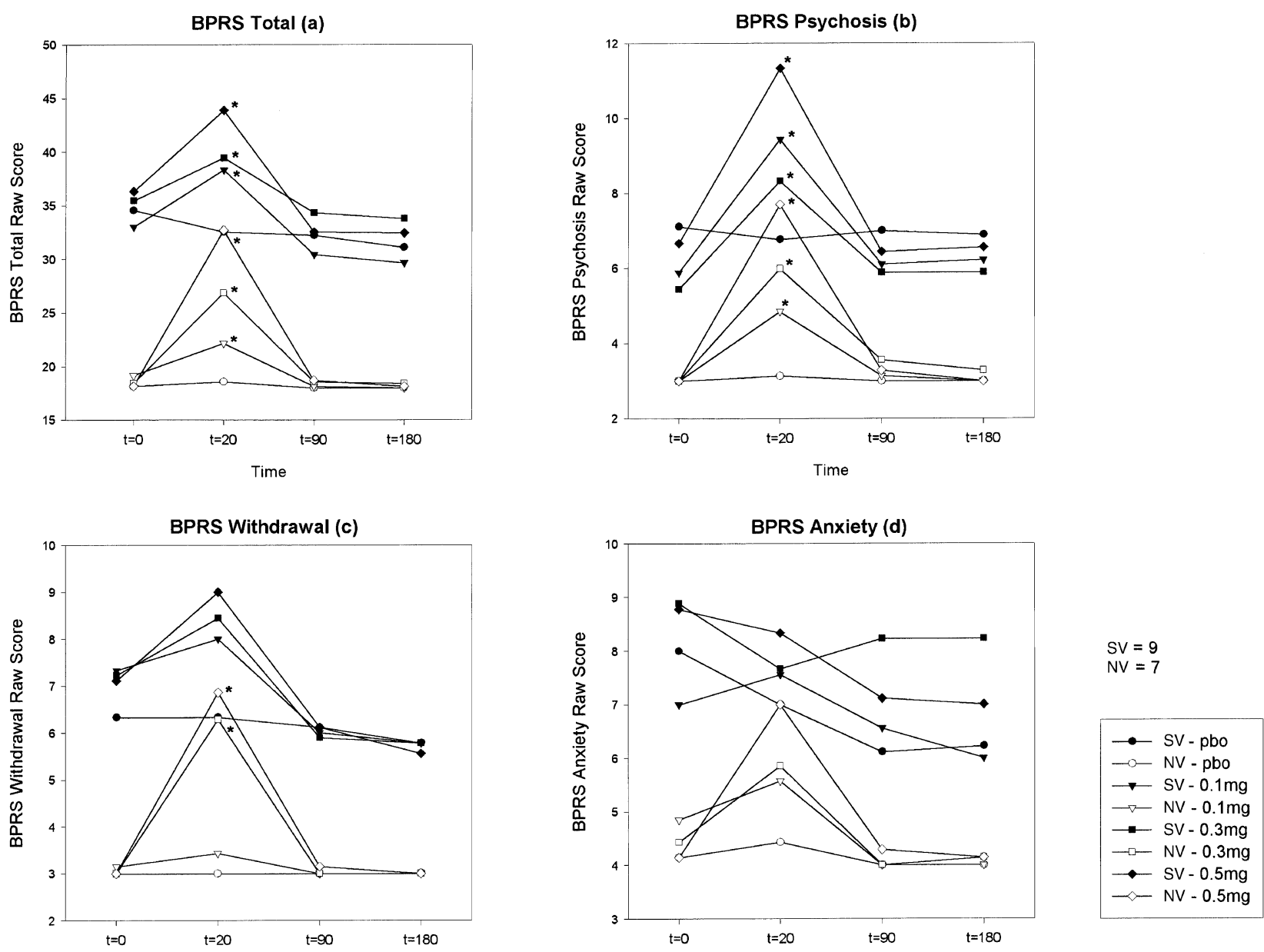

Figure 2. Time course of mental status after a dose range of ketamine doses $(0,1,0.3$ and $0.5 \mathrm{mg} / \mathrm{kg})$ and placebo in NVs $(n=$ 7) (open symbols) and SVs $(n=9)$ (closed symbols). Mean BPRS total and subscales scores are reported. Asterisk indicates a significant increase in mean change score at a given time point. For the BPRS total and psychosis scores, there was a doserelated significant increase at 20 min after ketamine in normal and SVs. The BPRS withdrawal significantly increased at 20 min for the higher doses in NVs only. The BPRS anxiety was elevated at a trend level at 20 min for the highest dose in NVs.

BPRS psychosis $\mathrm{F}[1,33]=51.70 ; p=.0001 ;$ BPRS withdrawal $\mathrm{F}[1,33]=11.48 ; p=.0018$; BPRS anxiety $\mathrm{F}[1,3]=$ $15.10 ; p=.0005$; BPRS hostility $\mathrm{F}[1,33]=19.74 ; p=$ .0001 ; BPRS activation $\mathrm{F}[1,33]=8.83 ; p=.0055)$. But, there were no significant interactions between group and dose, group and time, or group and dose and time for the BPRS total, the BPRS thought, anxiety, hostility, or activation scores.

On the BPRS withdrawal score, the analysis revealed a dose-by-group interaction $(\mathrm{F}[1,33]=4.44 ; p=.0428)$ and a trend for a dose-by-time-by-group interaction $(\mathrm{F}[3,31]=2.58 ; p=.07)$. To further contrast SV and NV's positive symptoms in response to ketamine, the BPRS psychosis subscale was split into two components: A thought disorganization score (item 4) and a hallucinations and delusions score (items 12 and 15). There was a main effect for group on both scores (item $4: \mathrm{F}[1,33]=11.41 ; p=.019$; items 12 and $15 \mathrm{~F}[1,33]=$
$53.95 ; p=.0001)$. But there were no significant interactions for neither of the two scores.

In summary, normal and schizophrenic groups responded similarly on BPRS total, psychosis, and anxiety measures. But on the BPRS withdrawal score, NVs experienced a more marked increase in the withdrawal score than SVs. We identified a trend for the groups to differ on the BPRS withdrawal score over time.

Multiple Dose. There was a significant group effect for the BPRS total score and all its subscales, except for the BPRS activation subscale (BPRS total $\mathrm{F}[1,14]=$ 37.66; $p=.0001$; BPRS psychosis $\mathrm{F}[1,14]=21.83 ; p=$ .0004 ; BPRS withdrawal $\mathrm{F}[1,14]=8.58 ; p=.0110$; BPRS hostility $\mathrm{F}[1,14]=15.47 ; p=.0015$; BPRS anxiety $\mathrm{F}[1,14]=$ 8.93; $p=.0098)$. There were no significant interactions between group and dose, group and time, and group and dose and time for the BPRS total, psychosis, with- 
Table 2b. BPRS Change Scores after Ketamine $(0.1,0.3,0.5 \mathrm{mg} / \mathrm{kg})$ and Placebo

\begin{tabular}{|c|c|c|c|c|c|c|c|c|c|c|c|c|c|}
\hline \multirow[b]{2}{*}{ Dose } & \multirow[b]{2}{*}{ Time } & \multicolumn{4}{|c|}{$\begin{array}{l}\text { BPRS } \\
\text { Total }\end{array}$} & \multicolumn{4}{|c|}{$\begin{array}{c}\text { BPRS } \\
\text { Psychosis }\end{array}$} & \multicolumn{4}{|c|}{$\begin{array}{c}\text { BPRS } \\
\text { Withdrawal }\end{array}$} \\
\hline & & SV & sd & NV & sd & SV & sd & NV & sd & SV & sd & NV & sd \\
\hline PBO & $20^{\prime}$ & -2 & 2.9 & 0.4 & 1 & -0.3 & 0.5 & 0.1 & 0.4 & 0 & 0.7 & 0 & 0 \\
\hline $0.1 \mathrm{mg}$ & & 5.3 & 8 & 3 & 2.2 & 3.6 & 1.8 & 1.9 & 1.2 & 0.7 & 2.8 & 0.3 & 0.5 \\
\hline $0.3 \mathrm{mg}$ & & 4 & 5.3 & 8.4 & 3.1 & 2.9 & 2.4 & 3 & 2 & 1.2 & 4 & 3.3 & 2.4 \\
\hline $0.5 \mathrm{mg}$ & & 7.6 & 8.4 & 14.6 & 4.2 & 4.7 & 3.7 & 4.7 & 2.4 & 1.9 & 4 & 3.9 & 2.9 \\
\hline $\mathrm{PBO}$ & $90^{\prime}$ & -2.3 & 4.3 & -0.1 & 0.4 & -0.1 & 0.3 & 0 & 0 & -0.2 & 0.7 & 0 & 0 \\
\hline $0.1 \mathrm{mg}$ & & -2.6 & 4.5 & -1 & 1.3 & 0.2 & 1.1 & 0.1 & 0.4 & -1.3 & 2.2 & -0.1 & 0.4 \\
\hline $0.3 \mathrm{mg}$ & & -1.1 & 4.7 & 0.1 & 0.7 & 0.4 & 1.2 & 0.6 & 0.8 & -1.3 & 2.3 & 0 & 0 \\
\hline $0.5 \mathrm{mg}$ & & -3.8 & 6.6 & 0.6 & 1 & -0.2 & 1.6 & 0.3 & 0.5 & -1 & 3.1 & 0.1 & 0.4 \\
\hline PBO & $180^{\prime}$ & -3.4 & 5.2 & -0.1 & 0.4 & -0.2 & 0.4 & 0 & 0 & -0.6 & 1.1 & 0 & 0 \\
\hline $0.1 \mathrm{mg}$ & & -3.3 & 4.1 & -1.1 & 1.1 & 0.3 & 1.9 & 0 & 0 & -1.6 & 2.6 & -0.1 & 0.4 \\
\hline $0.3 \mathrm{mg}$ & & -1.7 & 3.6 & 0 & 0.8 & 0.4 & 0.9 & 0.3 & 0.8 & -1.4 & 2.4 & 0 & 0 \\
\hline \multirow[t]{2}{*}{$0.5 \mathrm{mg}$} & & -3.9 & 4 & 0 & 0.6 & -0.1 & 1.4 & 0 & 0 & -1.6 & 2.1 & 0 & 0 \\
\hline & & \multicolumn{4}{|c|}{$\begin{array}{c}\text { BPRS } \\
\text { Anxiety }\end{array}$} & \multicolumn{4}{|c|}{$\begin{array}{c}\text { BPRS } \\
\text { Activation }\end{array}$} & \multicolumn{4}{|c|}{$\begin{array}{c}\text { BPRS } \\
\text { Hostility }\end{array}$} \\
\hline PBO & $20^{\prime}$ & -1 & 2.2 & 0.3 & 1 & -0.3 & 0.5 & 0 & 0 & -0.1 & -0.1 & 0 & 0 \\
\hline $0.1 \mathrm{mg}$ & & 0.6 & 2.5 & 0.7 & 1.8 & 1 & 2.8 & 0 & 0.6 & -0.6 & -0.6 & 0.1 & 0.4 \\
\hline $0.3 \mathrm{mg}$ & & -1.2 & 1.1 & 1.4 & 1.5 & 0.4 & 1.9 & 0 & 0 & 0.4 & 0.4 & 0.1 & 0.4 \\
\hline $0.5 \mathrm{mg}$ & & -0.4 & 4 & 2.9 & 2 & 0.9 & 2.3 & 1 & 1.73 & 0.4 & 0.4 & 0.7 & 1.1 \\
\hline PBO & $90^{\prime}$ & -1.9 & 2.6 & -0.1 & 0.4 & -0.2 & 1.1 & 0 & 0 & 0.2 & 0.2 & 0 & 0 \\
\hline $0.1 \mathrm{mg}$ & & -0.4 & 1.1 & -0.9 & 0.9 & 0 & 0.5 & -0.1 & 0.4 & -1.1 & -1.1 & 0 & 0 \\
\hline $0.3 \mathrm{mg}$ & & -0.7 & 2.6 & -0.4 & 0.5 & 0.1 & 1.3 & 0 & 0 & 0 & 0 & 0 & 0 \\
\hline $0.5 \mathrm{mg}$ & & -1.7 & 3 & 0.1 & 0.7 & -0.2 & 1.1 & 0 & 0 & -0.4 & -0.4 & 0 & 0 \\
\hline $\mathrm{PBO}$ & $180^{\prime}$ & -1.8 & 2.8 & -0.1 & 0.4 & -0.4 & 1 & 0 & 0 & -0.3 & -0.3 & 0 & 0 \\
\hline $0.1 \mathrm{mg}$ & & -1 & 1.2 & -0.9 & 0.9 & 0 & 0.5 & -0.1 & 0.4 & -0.8 & -0.8 & 0 & 0 \\
\hline $0.3 \mathrm{mg}$ & & -0.7 & 1.7 & -0.3 & 0.8 & 0 & 0.9 & 0 & 0 & -0.2 & -0.2 & 0 & 0 \\
\hline $0.5 \mathrm{mg}$ & & -1.8 & 3.2 & 0 & 0.6 & -0.1 & 1.1 & 0 & 0 & -0.1 & -0.1 & 0 & 0 \\
\hline
\end{tabular}

SV $N=9$.

$\mathrm{NV} N=7$.

drawal, and hostility. For the BPRS anxiety there was a trend for a significant time-by-group interaction $(\mathrm{F}[3,42]=3.02 ; p=.06)$.

In summary, patterns of ketamine response in normal and schizophrenic groups did not differ significantly on any of the BPRS scores. Regardless of dose, the NVs had an increase in anxiety at $20 \mathrm{~min}$ whereas SV showed a decrease or little change in anxiety across time and doses (Figure 2d). Although not significant, this pattern also with the $0.3 \mathrm{mg} / \mathrm{kg}$ vs. placebo comparison. (Figure 1).

Ketamine Plasma Level. Ketamine plasma levels were analyzed from samples taken during challenge with $0.3 \mathrm{mg} / \mathrm{kg}$ ketamine in $12 \mathrm{SVs}$ and $12 \mathrm{NVs}$. There were no significant differences in ketamine level between schizophrenic and normal controls at any time point sampled (Figure 3).

Correlations between Mental Status Changes and Baseline Symptomology/Demographics. There were no significant associations between any aspect of the symptom changes induced by ketamine and age, sex, or race for all volunteers (normal or schizophrenic). There were no significant correlations between ketamineinduced symptom changes and plasma ketamine levels in either normal or schizophrenic populations.

In SVs, we found no significant correlations between diagnosis, deficit symptoms, age of illness onset, length of illness, baseline symptoms, or change in symptoms during medication withdrawal, and any symptom change with ketamine.

For NVs, we identified a significant correlation between change in BPRS psychosis score at $20 \mathrm{~min}$ and two of the Wisconsin subscales [PER $(\mathrm{r}=0.53 ; p=.04)$ and PERMAG $(\mathrm{r}=.53 ; p=.04)]$. These two Wisconsin subscales measure perceptual distortions alone (PER) or combined with wrong attribution of causation (PERMAG) in normal persons.

\section{Clinical Observations}

Positive Symptoms. Figure $2 \mathrm{~b}$ demonstrates a similar dose-response pattern in all BPRS subscales in both normal and SVs, except for baseline values. Obviously, the SVs have higher baseline BPRS values. Although some aspects of the ketamine response of these two groups were similar (symptom type, for example), some as- 


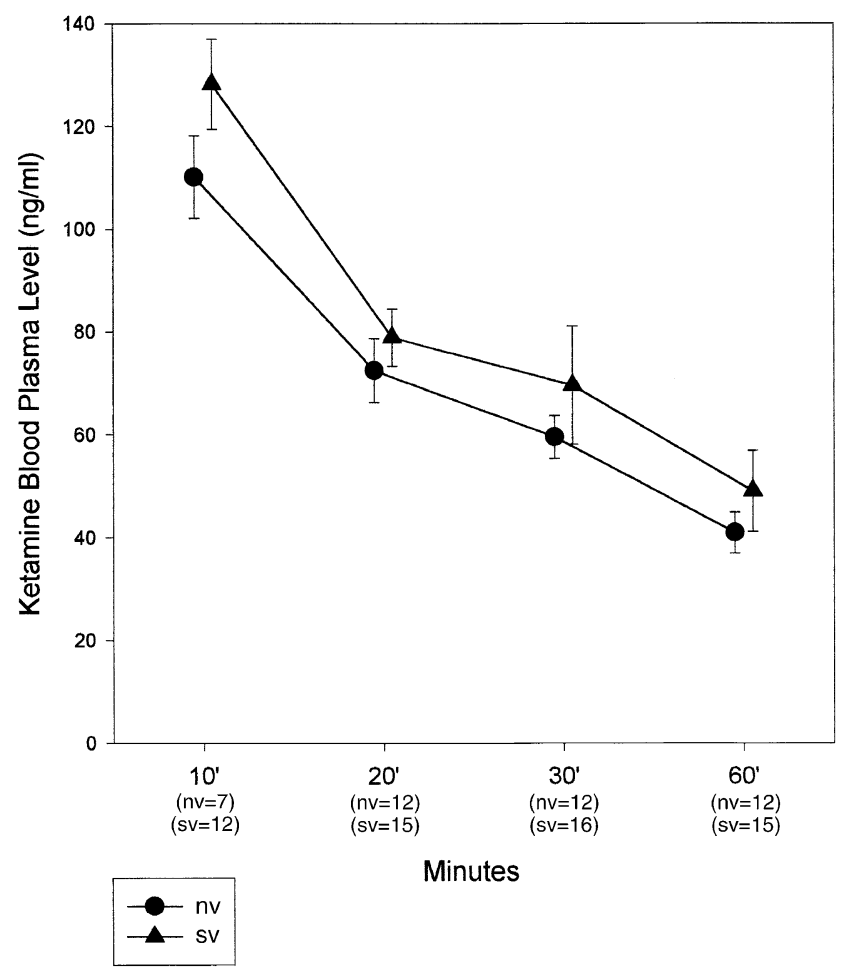

Figure 3. Time course of plasma ketamine concentrations for the $0.3 \mathrm{mg} / \mathrm{kg}$ challenge in normal and SVs. There were no significant differences between schizophrenic and normal controls.

pects of ketamine-induced behavioral changes between the two groups were different in several ways (Table 3). SVs experienced visual and auditory illusions, distortions, and somaesthetic sensations at the $0.1 \mathrm{mg} / \mathrm{kg}$ doses and unformed (e.g., buzzing, popping sounds) and formed (e.g., articulated voice) hallucinations at the $0.3 \mathrm{mg} / \mathrm{kg}$ and $0.5 \mathrm{mg} / \mathrm{kg}$ doses. On the other hand, throughout the ketamine dose range, NVs experienced illusions and perceptual distortions and less frequently perception without external stimuli (e.g., popping sounds) or unusual, odd thought (idea of reference, participating in a study for aliens). These kinds of symptoms can be seen in schizophrenic persons with very low levels of positive symptoms and have been typically seen as the start of a "psychosis" spectrum (Astrachan et al. 1972). Formed hallucinations were rarely reported by NVs at the doses used here. However, both subject groups experienced thought disorganization (looseness of association, concreteness, bizarre reasoning) at all doses.

Schizophrenics experienced two kinds of symptoms. First, they had delusions whose theme and content reminded them of delusions they had previously experienced during an acute psychotic state (particularly grandiose and paranoid delusions). Second, they experienced unformed psychotic symptoms similar to those experienced by NVs. Approximately $70 \%$ of the pa- tients experienced some ketamine-induced symptoms reminiscent of their usual psychotic symptoms during an illness exacerbation.

NVs experienced formed mental images, which they described as a dream, movie, or cartoon. Their themes were occasionally paranoid. Occasionally, NVs evidenced a "true" schizophrenic-like psychotic symptom, such as an idea of reference (two NVs). Sometimes, schizophrenics reported their experience without insight as though they were reporting their usual illnessassociated symptoms. One patient spontaneously made the parallel between the current ketamine interview and his acute symptoms; another connected this experience with a need to take further anti-psychotic medication. NVs always commented on how the experience was unusual, bizarre.

Negative Symptoms. Only NVs showed an increase in withdrawal scores with ketamine, increases that were significant for the 0.3 and $0.5 \mathrm{mg} / \mathrm{kg}$ dose level. None of the changes were significant for the patient volunteers. NVs displayed negative symptoms based on their blunted facial expression; often they remained silent during the first minutes of the experiment. However, after the session, they always reported their mental experiences with ketamine in an involved and animated fashion lacking the typical curbing of interest and diminished social drive that are intrinsic to the negative symptoms spectrum. Thus, ketamine induced only some of the dimensions of negative symptoms.

\section{DISCUSSION}

These data show that subanesthetic doses of ketamine in healthy and SVs induce a mild, dose-related, shortlasting increase in psychotic symptoms. The design carried out in this experiment contrasts responses of the two populations: some responses were similar (e.g., on positive symptoms), and some were also different (e.g., on negative symptoms). To enable the comparison, we have compared adequate groups of patients and NVs across a subanesthetic dose range, analyzing the pattern of changes produced.

All of the normal and patient volunteers who received ketamine experienced psychotic symptoms. Although the normal and patient individuals had different levels of baseline psychosis, the magnitude and time course of ketamine-induced changes were similar, and the dose-response profile in BPRS-rated positive symptoms changes was parallel across the two populations. This behavioral result is consistent with the functional regional cerebral blood flow studies of ketamine in normal and SVs, which have shown similar activation patterns and dynamics between the two groups (Lahti et al. 1995b, 1999) (Holcomb et al. in press). Both groups experienced thought disorganization, such 
Table 3.

\begin{tabular}{|c|c|c|c|}
\hline NV & Acute Drug Effect & SV & Acute Drug Effect \\
\hline 1 & $\begin{array}{l}\text { False beliefs (participating in study for aliens), anxiety, } \\
\text { perceptual distortion, confusion, thought } \\
\text { disorganization }\end{array}$ & 1 & $\begin{array}{l}\text { A typical visual hallucinations, reduced emotional } \\
\text { withdrawal and blunted affect }\end{array}$ \\
\hline 2 & $\begin{array}{l}\text { False beliefs (like being in the movie 2001), thought } \\
\text { disorganization, confusion (time), perceptual } \\
\text { distortion (somaesthetic \& visual) }\end{array}$ & 2 & $\begin{array}{l}\text { Suspiciousness, visual hallucinations, increased } \\
\text { withdrawal and blunted affect }\end{array}$ \\
\hline 3 & $\begin{array}{l}\text { Ideas of reference, perceptual distortions (visual), } \\
\text { anxiety, confusion (time), "tunnel vision" }\end{array}$ & 3 & $\begin{array}{l}\text { Perceptual distortions-illusions, increased suspiciousness, } \\
\text { delusions of control, auditory hallucinations, atypical } \\
\text { visual hallucinations }\end{array}$ \\
\hline 4 & $\begin{array}{l}\text { Anxiety, perceptual distortion (somaesthetic \& visual), } \\
\text { out-of-body experience, auditory buzzing, idea of } \\
\text { reference (people could hear her thoughts) }\end{array}$ & 4 & $\begin{array}{l}\text { Increased thought disorder, paranoid ideation, } \\
\text { visual hallucinations }\end{array}$ \\
\hline 5 & Perceptual distortions (somaesthetic, auditory) & 5 & $\begin{array}{l}\text { Perceptual distortions-illusions, atypical visual } \\
\text { hallucinations }\end{array}$ \\
\hline 6 & $\begin{array}{l}\text { Visual hallucination, perceptual distortions (auditory, } \\
\text { visual), olfactory hallucination }\end{array}$ & 6 & Grandiose delusions \\
\hline 7 & Perceptual distortion (visual) & 7 & $\begin{array}{l}\text { Disorganized thought (word salad), grandiose } \\
\text { delusions }\end{array}$ \\
\hline 8 & $\begin{array}{l}\text { Overinclusiveness, perceptual distortion (visual, } \\
\text { auditory, somaesthetic), illusions }\end{array}$ & 8 & No reported change \\
\hline 9 & $\begin{array}{l}\text { Perceptual distortions (visual, auditory, somaesthetic), } \\
\text { synesthesia, auditory hallucinations }\end{array}$ & 9 & Auditory hallucinations \\
\hline 10 & $\begin{array}{l}\text { Emotional withdrawal, perceptual distortion (visual, } \\
\text { auditory), conceptual disorganization }\end{array}$ & 10 & $\begin{array}{l}\text { Excitement, conceptual disorganization, suspiciousness, } \\
\text { paranoid delusion }\end{array}$ \\
\hline 11 & $\begin{array}{l}\text { Perceptual distortions (auditory, visual, somaesthetic), } \\
\text { euphoria, thought disorganization }\end{array}$ & 11 & $\begin{array}{l}\text { Excitement, conceptual disorganization, perceptual } \\
\text { distortion (auditory), paranoid delusion }\end{array}$ \\
\hline 12 & $\begin{array}{l}\text { Perceptual distortion (visual, auditory, somaesthetic), } \\
\text { emotional withdrawal }\end{array}$ & 12 & Perceptual distortion, increase auditory hallucinations \\
\hline 13 & $\begin{array}{l}\text { Delusional perception, perceptual distortion (visual, } \\
\text { auditory, somaesthetic), excitement }\end{array}$ & 13 & $\begin{array}{l}\text { Increased auditory hallucinations, delusions of control, } \\
\text { somaesthetic distortion, disorganization }\end{array}$ \\
\hline 14 & $\begin{array}{l}\text { Disorientation, perceptual distortion (auditory, } \\
\text { visual, somaesthetic) }\end{array}$ & 14 & Somaesthetic distortions \\
\hline 15 & $\begin{array}{l}\text { Emotional withdrawal, perceptual distortion (auditory, } \\
\text { visual, somaesthetic), thought disorganization }\end{array}$ & 15 & $\begin{array}{l}\text { Increased disorganization, increased auditory } \\
\text { hallucinations, increased delusions, increased anxiety }\end{array}$ \\
\hline 16 & $\begin{array}{l}\text { Emotional withdrawal, auditory hallucinations, } \\
\text { somaesthetic distortion }\end{array}$ & 16 & Anxiety, visual distortion, out of body experience \\
\hline 17 & Emotional withdrawal, auditory hallucinations & 17 & Increased disorganization, increased religious delusions \\
\hline 18 & $\begin{array}{l}\text { Auditory hallucinations, disorientation, suspiciousness, } \\
\text { perceptual distortion (visual), anxiety, thought } \\
\text { disorganization }\end{array}$ & & \\
\hline
\end{tabular}

as concreteness and loose association. With respect to hallucinations, the NVs experienced mostly perceptual changes, but in more than $70 \%$ of patients the positive symptoms included previously experienced symptoms such as hallucinations and delusions. Others have also reported the similarity between normal and SVs in positive symptoms with ketamine (Adler et al. 1999). Thus, ketamine appears to induce hallucinatory and delusional symptoms along a gradient of intensity. NVs experience symptoms at the putative low end of the spectrum (simple illusion, perceptual distortion, formed mental images), and already-psychotic schizophrenic patients experience symptoms at the high end of the spectrum (formed hallucination, reactivation of delusional beliefs).

Only the NVs had a significant increase in the withdrawal subscale of the BPRS. And in that volunteer population, only some of the dimensions of negative symptoms, such as blunted affect and emotional withdrawal, were induced by ketamine. SVs had higher negative symptoms ratings at baseline and showed a nonsignificant rise in response to ketamine, possibly indicating a ceiling effect. Ketamine may increase only secondary negative symptoms in the NVs (secondary to experiencing altered perceptual experience for example). Reports of acute PCP intoxication in humans account primarily productive states (Pearlson 1981) whereas descriptions of chronic PCP abuse include characteristics of dulled thinking and lethargy (Cosgrove and Newell 1991). Others have reported ketamine-induced changes in negative symptoms, both in patient and NVs (Malhotra et al. 1997a). A difference in drug administration (acute bolus vs. slow infusion) could account for this, by inducing only a brief ket- 
amine period with the bolus technique. Such differences between acute bolus and chronic/subchronic infusion administration would be predicted by animal studies with PCP where neurochemical and behavioral differences between those two states can be found (Jentsch et al. 1998; Jentsch and Roth 1999).

The finding of close similarity between ketamineinduced symptoms and the SV's own symptoms and their exacerbation with ketamine suggest that glutamatergic hypofunction may be close to the pathophysiology of positive psychotic symptoms in schizophrenia. The lack of blockade in patient volunteers with the traditional antipsychotic haloperidol (Lahti et al. 1995a), but the reported blunting of response with clozapine (Malhotra et al. 1997b) is intriguing. Thus the ketamine model may represent a useful human model of psychosis with hallucinations, delusions, and thought disturbances, and an opportunity for novel pharmacology.

Several studies have reported changes in measures of cognition, eye-tracking, and event-related brain potentials with ketamine in normal (Harborne et al. 1996; Radant et al. 1998; vanBerckel et al. 1998; Oranje et al. 2000; Weiler et al. 2000) and SVs (LaPorte et al. 1996; Malhotra et al. 1997a). These results suggest that ketamine, when further studied, may induce additional symptoms of schizophrenia, particularly the cognitive.

Among models of schizophrenic psychosis, dopamine has been the most widely studied based on several observations: that repeated administrations of amphetamine can induce paranoid symptoms (see Introduction for review), that all effective antipsychotic drugs block $\mathrm{D}_{2}$ dopamine receptor, and that their affinity for this receptor correlates positively with drug potency (Creese 1976; Seeman et al. 1976). Recently evidence of augmented dopamine release in schizophrenia has been reported (Laruelle et al. 1996). However, administration of a dopamine agonist to persons with schizophrenia can induce a heterogeneous symptom response. When worsening occurs, it is mostly limited to paranoid symptoms. Dopamine agonists increase psychotic symptoms in subacute patients and the response may be predictive of relapse (Lieberman et al. 1987). These characteristics have been interpreted as indicating that dopamine agonist-induced psychosis in schizophrenia is a state-dependent phenomenon produced by increased DA neuronal activity (Janowsky et al. 1973).

These characteristics stand in contrast to what is seen with ketamine. Ketamine increases symptoms in all SVs and in a way that is strikingly reminiscent of subjects' symptoms during active episodes of illness. Traditional antipsychotics, such as haloperidol, do not reverse these symptoms (Lahti et al. 1995a). There is no correlation between ketamine psychosis and baseline symptomology, and the change in psychosis is not predictive of symptom worsening during medication withdrawal. Thus, ketamine exacerbates symptoms of the illness un- related to the current clinical state. Putatively, ketamine may induce a neurochemical abnormality related to the core of the illness.

Ketamine is an anesthetic drug with a strong record of safety. Ketamine is commonly used at doses 20-60 times higher than doses administered here. The increase in psychosis with ketamine in this paradigm is short (20-30 min), and our ratings show that the mental status of all volunteers' returns to baseline by $90 \mathrm{~min}$. Distress is minimal, especially in patients, as shown by a lack of any change in the BPRS anxiety score. Outcome studies in patients who received ketamine have shown that ketamine administration does not complicate the course of schizophrenic illness for the next eight months after challenge beyond the immediate post-ketamine 30-min time period (Carpenter 1999; Lahti et al. 2001).

These data show that the putative antagonism of NMDA-sensitive glutamatergic transmission with ketamine provokes schizophrenia-like psychotic symptoms in normal controls and exacerbates specific symptoms of schizophrenia in the patient group. Therefore, the ketamine administration may provide a valid human model of psychosis. Because ketamine-induced psychosis is not blocked by haloperidol, and only blunted by clozapine, it also provides a surrogate marker of enhanced antipsychotic activity and should be evaluated further for its usefulness in new drug development (Lahti et al. 1999). New compounds with new modes of action could be screened in this model. Our study indicates that NVs can be used along side of the SVs because the symptom profile and time course with ketamine is parallel across groups. Where possible, healthy volunteers can validly be used; where necessary, patient volunteers can participate.

\section{ACKNOWLEDGMENTS}

This ketamine research was supported in part by grant DA09483 and for subject characteristic by MH40279. The authors thank all of the schizophrenic and normal volunteers who took part in these research studies, the staff of the Residential Research Unit of the Maryland Psychiatric Research Center, Kristin Frey Deb Medoff and Bob McMahon for statistical expertise, Thomas Cooper for plasma ketamine assays determination, and Kristin Ricasa for her administrative assistance.

\section{REFERENCES}

Adler CM, Malhotra AK, Elman I, Goldberg T, Egan M, Pickar D, Breier A (1999): Comparison of ketamineinduced thought disorder in healthy volunteers and thought disorder in schizophrenia. Am J Psychiatry 156:1646-1649

Aghajanian GK, Marek GJ (1999): Serotonin and hallucinogens. Neuropsychopharmacology 21:16S-23S 
Angrist BM, Gershon S (1970): The phenomenology of experimentally induced amphetamine psychosis: Preliminary observations. Biol Psychiatry 2:95-107

Anis NA, Berry SC, Burton NR, Lodge D (1983): The dissociative anesthetics, ketamine and phencyclidine, selectively reduce excitation of central mammalian neurones by N- methyl-D-aspartate. Br J Pharmacol 79:565-575

Astrachan BM, Harrow M, Adler D, Brauer L, Schwartz A, Schwartz C, Tucker G (1972): A checklist for the diagnosis of schizophrenia. Br J Psychiatry 121:529-539

Bell DS (1973): The experimental reproduction of amphetamine psychosis. Arch Gen Psychiatry 29:35-40

Cannon-Spoor HE, Potkin SG, Wyatt RJ (1982): Measurement of premorbid adjustment in chronic schizophrenia. Schizophr Bull 8:470-484

Carlsson M, Carlsson A (1990): Interactions between glutamatergic and monoaminergic systems within the basal ganglia - implications for schizophrenia and Parkinson's disease. Trends Neurosci 13:272-276

Carpenter WT (1999): The schizophrenia ketamine challenge study debate. Biol Psychiatry 46:1081-1091

Cassady SL, Thaker GK, Summerfelt A, Tamminga CA (1997): The Maryland Psychiatric Research Center scale for the characterization of involuntary movements. Psychiatry Res 70:21-37

Castellani S, Adams PM (1981): Effects of dopaminergic drugs on phencyclidine-induced behavior in the rat. Neuropsychopharmacology 20:371-374

Chapman LJ, Chapman JP, Kwapil TR, Eckblad M, Zinser MC (1994): Putatively psychosis-prone subjects 10 years later. J Abn Psychol 103:171-183

Connell PH (1958): Amphetamine psychosis. Maudsley Monograph No. 5. London, Oxford University Press

Cosgrove J, Newell TG (1991): Recovery of neuropsychological functions during reduction in use of phencyclidine. J Clin Psychol 47:159-169

Coyle JT, Puttfarcken P (1993): Oxidative stress, glutamate, and neurodegenerative disorders. Science 262:689-695

Creese I (1976): Dopamine receptor binding predicts clinical and pharmacological potencies of antischizophrenic drugs. Science 192:481-483

Giannini AJ (1994): Inward the mind's I: Description, diagnosis, and treatment of acute and delayed LSD hallucinations. Psychiatric Ann 24:134-136

Griffith JD, Cavanaugh J, Oates J (1968): Paranoid episodes induced by drug. JAMA 205:39

Harborne GC, Watson FL, Healy DT, Groves L (1996): The effects of sub-anaesthetic doses of ketamine on memory, cognitive performance and subjective experience in healthy volunteers. J Psychopharmacol 10:134-140

Hedlund JL, Vieweg BW (1980): The brief psychiatric rating scale (BPRS): A comprehensive review. J Oper Psychiatry 11:48-64

Holcomb HH, Lahti AC, Medoff D, Weiler MA, Tamminga CA (2001): Sequential regional cerebral blood flow brain scans using PET with $\mathrm{H}_{2}^{15} \mathrm{O}$ demonstrate ketamine actions in CNS dynamically. Neuropsychopharmacology 25:165-172

Janowsky DS, el-Yousel MK, Davis JM, Sekerke HJ (1973): Provocation of schizophrenic symptoms by intravenous administration of methylphenidate. Arch Gen Psychiatry 28:185-191

Javitt DC, Zukin SR (1991): Recent advances in the phencyclidine model of schizophrenia [Review]. Am J Psychiatry 148:1301-1308

Jentsch JD, Roth RH (1999): The neuropsychopharmacology of phencyclidine: From NMDA receptor hypofunction to the dopamine hypothesis of schizophrenia. Neuropsychopharmacology 20:201-225

Jentsch JD, Taylor JR, Roth RH (1998): Subchronic phencyclidine administration increases mesolimbic dopaminergic system responsivity and augments stress- and psychostimulant-induced hyperlocomotion. Neuropsychopharmacology 19: 105-113

Kirkpatrick B, Buchanan RW, McKenney PD, Alphs LD, Carpenter WT (1989): The schedule for the deficit syndrome: An instrument for research in schizophrenia. Psychiatry Res 30:119-123

Kornhuber J, Weller M (1995): Predicting psychotomimetic properties of PCP-like NMDA receptor antagonists. In Fog R, Gerlach J, Hemmingsen R, Krogsgaard-Larsen P, Thaysen JH (eds), Schizophrenia-an Integrated View. Alfred Benzon Symposium 38, Munksgaard, Copenhagen, pp 314-325

Krystal JH, Karper LP, Seibyl JP, Freeman GK, Delaney R, Bremner D, Heninger GR, Bowers MB, Charney DS (1994): Subanesthetic effects of the noncompetitive NMDA antagonist, ketamine, in humans: Psychotomimetic, perceptual, cognitive, and neuroendocrine responses. Arch Gen Psychiatry 51:199-214

Lahti AC, Holcomb HH, Gao XM, Tamminga CA (1999): NMDA-sensitive glutamate antagonism: A human model for psychosis. Neuropsychopharmacology 21: S158-S169

Lahti AC, Holcomb HH, Medoff DR, Tamminga CA (1995b): Ketamine activates psychosis and alters limbic blood flow in schizophrenia. Neuroreport 6:869-872

Lahti AC, Koffel B, LaPorte D, Tamminga CA (1995a): Subanesthetic doses of ketamine stimulate psychosis in schizophrenia. Neuropsychopharmacology 13:9-19

Lahti AC, Warfel D, Michaelidis T, Weiler MA, Frey K, Tamminga CA (2001): Long-term outcome of patients who receive ketamine during research. Biol Psychiatry, 49: 869-875

Langs RJ, Barr HL (1968): Lysergic acid diethylamide (LSD25) and schizophrenic reactions. J Nerv Mental Dis 147: 163-172

LaPorte DJ, Lahti AC, Koffel B, Tamminga CA (1996): Absence of ketamine effects on memory and other cognitive functions in schizophrenia. J Psychiatr Res 30: 321-330

Laruelle M., Abi-Dargham A, vanDyck CH, Gil R, D'Souza CD, Erdos J, McCance E, Rosenblatt W, Fingado C, Zoghbi SS, Baldwin RM, Seibyl JP, Krystal JH, Charney DS, Innis RB (1996): Single photon emission computerized tomography imaging of amphetamine-induced dopamine release in drug-free schizophrenic subjects. Proc Natl Acad Sci U S A 93:9235-9240

Lieberman JA, Kane JM, Alvir JAJ (1987): Provocative tests with psychostimulant drugs in schizophrenia. Psychopharmacology 91:415-433

Luby ED, Cohen BD, Rosenbaum G, Gottlieb JS, Kelley R 
(1959): Study of a new schizophrenomimetic drug: serenyl. Arch Neurol Psychiatry 71:363-369

Malare A, Holsapple MP, Yim GK (1982): Reduction by atropine of phencyclidine hypertension and apneusis. Life Sci 30:929-934

Malhotra AK, Pinals DA, Adler CM, Elman I, Clifton A, Pickar D, Breier A (1997a): Ketamine-induced exacerbation of psychotic symptoms and cognitive impairment in neuroleptic-free schizophrenics. Neuropsychopharmacology 17:141-150

Malhotra AK, Adler CM, Kennison SD, Elman I, Pickar D, Breier A (1997b): Clozapine blunts N-Methyl-D-Aspartate antagonist-induced psychosis: A study with ketamine. Biol Psychiatry 42:664-668

Nabeshima T, Sivam SP, Norris JC, Ho IK (1981): Calciumdependent GABA release from mouse brain slices following acute and chronic phencyclidine administration. Res Commun Subst Abuse 2:343

Olney JW, Farber NB (1995): Glutamate receptor dysfunction and schizophrenia. Arch Gen Psychiatry 52:9981007

Oranje B, vanBerckel BN, Kemner C, vanRee JM, Kahn RS, Verbaten MN (2000): The effects of a sub-anaesthetic dose of ketmaine on human selective attention. Neuropsychopharmacology 22:293-302

Overall JE, Gorham DR (1962): The Brief Psychiatric Rating Scale. Psychol Rep 10:799-812

Oye I, Hustveit O, Maurset A, Ratti Moberg E, Paulsen O, Skoglund LA (1991): The chiral forms of ketamine as probes for NMDA-receptor function in humans. In Kameyama T, Nabeshima T, Domino EF (eds), NMDA receptor related agents: Biochemistry, Pharmacology and Behavior. Ann Arbor, NPP Books, pp 381-389

Pearlson GD (1981): Psychiatric and medical syndromes associated with phencyclidine (PCP) abuse. John Hopkins Med J 148:25-33

Radant AD, Bowdle TA, Cowley DS, Kharasch ED, Roy-
Byme PP (1998): Does ketamine-mediated N-methylD-aspartate receptor antagonism cause schizophrenialike oculomotor abnormalities? Neuropsychopharmacology 19:434-444

Raja SN, Guyenet PG (1980): Effects of phencyclidine on the spontaneous activity of monoaminergic neurons. Eur J Pharmacol 63:229-233

Seeman P, Lee T, Chau-Wong M, Wong K (1976): Antipsychotic drug doses and neuroleptic-dopamine receptors. Nature 261:717-719

Spitzer RL, Williams JBW, Gibbon M, First MB (1990): Structured Clinical Interview for DSM III-R (SCID) PB. New York, NY, New York State Psychiatric Institute, Biometrics Research Department

Stangl D, Pfohl B, Zimmerman M (1985): A structured interview for the DSM III personality disorders: A preliminary report. Arch Gen Psychiatry 42:591-596

Strauss JS, Carpenter WT (1974): The prediction of outcome in schizophrenia. Arch Gen Psychiatry 31:37-42

Tonge SR, Leonard BE (1969): The effects of some hallucinogenic drugs upon the metabolism of 5-hydroxytryptamine in the brain. Life Sci 8:805-814

vanBerckel BN, Oranje B, Ree JMV, Verbaten MN, Kahn RS (1998): The effects of low dose ketamine on sensory gating, neuroendocrine secretion and behavior in healthy human subjects. Psychopharmacology 137:271-281

vanKammen DP, Bunney WE, Docherty JP, Marder SR, Ebert MH, Rosenblatt JE, Rayner JN (1982): d-amphetamine-induced heterogeneous changes in psychotic behavior in schizophrenia. Am J Psychiatry 139:991-997

Vollenweider EX, Vollenweider-Scherpenhuyzen MF, Babler A, Vogel H, Hell, D (1998): Psilocybin induces schizophrenia-like psychosis in humans via a serotonin2 agonist action. Neuroreport 9(17):3897-902

Weiler MA, Thaker GK, Lahti AC, Ross DE, Tamminga CA (2000): Effects of ketamine on eye tracking in normal controls. Neuropsychopharmacology, 23:645-653 